\title{
Role of Pharmacist in Improving Health Related Quality of Life (HRQoL) in Hypertensive Pateints in Pakistan
}

\author{
Muhammad Masoom Akhtar,,", Akbar Waheed ${ }^{2}$, Dilnawaz Sheikh ${ }^{3}$, Azhar Hussain ${ }^{1}$ \\ ${ }^{1}$ Department of Pharmacy, Hamdard Institute of Pharmaceutical Sciences, Islamabad, Pakistan \\ ${ }^{2}$ Department of Pharmacology, Army Medical College, Rawalpindi, Pakistan \\ ${ }^{3}$ Faculty of Pharmacy, Hamdard University, Sharae Madina Al Hikmah,Karachi, Pakistan \\ *Corresponding author: akhtar.masoom@gmail.com
}

Received October 15, 2014; Revised November 20, 2014; Accepted December 04, 2014

\begin{abstract}
Health related quality of life (HRQoL) is used to measure both the present health status and the impact of health care interventions on the patients. The aim of the present study is to evaluate the improvement in health related quality of life of the hypertensive patients after pharmaceutical care provided by pharmacist in Pakistan. A repeated measure prospective intervention study was conducted at Armed Forces Institute of Cardiology, Rawalpindi, Pakistan. 286 hypertensive patients were enrolled at baseline, out which 116 patients kept enrolled till the end of the study. After taking the demographic data at baseline, the health related quality of life was measured by using the Urdu version of generic EQ-5D instrument of Euroqol Group at baselines and follow up visits after 2 months, 4 months and 6 months. All the data was entered and analyzed by using SPSS version 16 . Paired $t$ test and Pearson's correlation coefficient were performed to compare EQ-5D values and association between baselines and follow up visits. The EQ-5D Index score and EQ-5D VAS score were $0.8789 \pm 0.17993$ and $65.56 \pm 16.67$ at baseline which were raised to $0.9276 \pm 0.1392$ and $78.00 \pm 12.649$ respectively after 6 months. The study showed that health related quality of life of these hypertensive patients were significantly improved after pharmaceutical care interventions.
\end{abstract}

Keywords: Diastolic blood pressure (DBP), EuroQol five-dimension scale (EQ-5D), Health related quality of life (HRQoL), Systolic blood pressure (SBP)

Cite This Article: Muhammad Masoom Akhtar, Akbar Waheed, Dilnawaz Sheikh, and Azhar Hussain, "Role of Pharmacist in Improving Health Related Quality of Life (HRQoL) in Hypertensive Pateints in Pakistan." American Journal of Pharmacological Sciences, vol. 2, no. 5B (2014): 17-22. doi: 10.12691/ajps-2-5B-5.

\section{Introduction}

Health related quality of life (HRQoL) is as important as the quantity of life and it is used to measure both; the health status of patient and the impact of health care interventions [2]. The term HRQoL refers to the physical, emotional and social impact of disease and treatments and is distinct from physiologic measures of disease. Symptoms have a greater impact on HRQoL than patient characteristics, blood pressure or drug-related factors. Health-related quality of life (HRQoL) might be influenced by symptoms, whether these are derived from disease or treatment [3]. Patients with hypertension frequently report symptoms that are similar to those reported by patients without the diagnosis. Although hypertension is often thought to be asymptomatic, cognitive changes, mood alterations, and general symptoms, such as dizziness and headache attributable to hypertension have been depicted [4]. Drugs used for the treatment of hypertension also may cause symptoms, some of which are specific to a particular drug, whereas others are similar to symptoms described or attributed to the disease of hypertension. Physiologic changes due to illness or treatment lead to symptoms, which in turn influences functional status or HRQoL was proposed in Conceptual Model of Patient Outcomes by Wilson and Cleary in 1995. This model further recommended that relationships are influenced by patient and environmental variables that may affect patient perceptions of symptoms and changes in HRQoL. The strength of relationships between patient, disease, treatment variables, symptoms and HRQoL can be assessed by applying this model [5]. Hypertension complications are responsible for 9.4 million deaths annually in the world. The major complications of hypertension are ischemic heart disease and stroke that causing $45 \%$ and $51 \%$ deaths respectively per year in the world [6]. The primary goal of the treatment of a hypertensive patient is the reduction of the long-term risk of cardiovascular morbidity and mortality and improvement in health related quality of life. Healthrelated quality of life (HRQoL) in clinical medicine is as 'the functional effect of an illness and its consequent therapy upon a patient, as perceived by the patient'[7]. National Health and Nutrition Examination Survey conducted from 2001 to 2004 related the hypertension and its awareness to the lower health-related quality of life. Antihypertensive medication was associated with more physically unhealthy days, while there were no differences 
in health-related quality of life by control status [8]. A recent systematic review and meta-analysis of observational studies of HRQoL in hypertensive patients also concluded that HRQoL concerning physical functioning and general health is reduced in hypertensive patients who are aware of their condition, but not in patients who are unaware of their hypertension status [9]. Blood pressure-related symptoms, adverse drug effects, newly diagnosed type 2 diabetes and obesity might be associated with deterioration of HRQoL [10]. Early recognition of participants with these chronic diseases might therefore be considered to be of importance, not only in clinical disease management, but also in participant education and empowerment aimed at improving their HRQoL [11]. Pharmaceutical care has been defined as the responsible provision of drug therapy for the purpose of achieving defined outcomes that improve a patient's quality of life [12]. Pharmacists have been encouraged to provide pharmaceutical care to identify, prevent, resolve drug therapeutic problems and mediate dialogue with patients and physicians $[13,14,15]$. The improvement in patients' blood pressure control by the involvement of pharmacists in ambulatory care of hypertension in various courtiers has been reported $[16,17,18]$. Pharmaceutical Care intervention can be an effective method in improving BP control in elderly outpatients, reducing the risk that hypertension represents for cardiovascular disease [19]. Increased awareness of the disease as well as improved pharmacist patient and physician interaction may facilitate drug therapy modifications that are necessary to achieve desired BP goals. Various studies have reported positive influence of pharmacists on outpatient BP control [18,20,21,22,23,24].

HRQoL is an important aspect of social sciences that is often neglected. Various factors including shortage of professionals, health care facilities, income disparity and living status between the population subgroups have a profound impact on HRQoL in Pakistan. Besides that, lack of basic health facilities and recourses inversely affect health status and HRQoL of the population in general and specifically for patients suffering from chronic diseases like hypertension. Hypertension was reported to exert adverse effect on patients' well-being and HRQoL in Pakistan [25]. The pharmaceutical care concept and the role of the pharmacist in patient care are mainly popular in developed countries and several studies have been done in related areas. But the pharmacist involvement in patient care is still not well recognized in developing countries like Pakistan where the resources are limited and pharmacist are still recognized as mere 'drug seller' [26,27]. Taking all the above arguments into consideration this study was aimed to assess and quantify the impact of pharmaceutical care intervention provided by pharmacist in terms of health-related quality of life outcomes of the patients.

\section{Methodology}

\subsection{Study Design}

This study was designed to assess the role of pharmacist to improve the health related quality of life of hypertensive patients and whether BP could be better controlled with physician/ pharmacist collaborative team compared to usual care. This is a repeated measure prospective intervention study was designed to evaluate the improvement in health related quality of life of hypertensive patients after providing pharmaceutical care. This study design specifically examines whether patients in an intervention improve or become worse off during the course of the intervention, and then attributes any such improvement or deterioration to the intervention. The term 'follow-up' used in the present study indicates the patients' assessment follow-ups after 2 months, 4 months and 6 months while the term 'visit' indicates their appointment with the doctors, nurses and pharmacist in between the assessment follow-ups.

\subsection{Study Location and Time Frame}

The study was conducted at a consultant's cardiology OPDs of Armed Forces Institute of Cardiology (AFIC), Rawalpindi. It is a tertiary care hospital which provides health care facilities to the serving and retired army officers and federal government employees. The hospital consists of both clinical and non-clinical specialty departments. This study was carried out over six months. Patients were followed up for six months from their date of enrolment in the study during their hospital visits.

\subsection{Ethical Approval from Hospital for Undertaking the Study}

There is no ethical committee for clinical studies in Pakistan. Therefore, permission from the respective commandant of the hospital was taken to conduct the study.

\subsection{Consent from Study Patients}

After informing patients about research objectives, confidentiality of their information and disease condition and they could withdraw at any time during the study without any penalty or affect on their treatment, the written consent was taken.

\subsection{Study Population and Sample Size}

For this interventional study, a sample of 286 hypertension patients was selected. As the present research was designed as a follow-up study for six months, a dropout rate was anticipated. Thus, 108 patients remained enrolled till the end of the study. Convenient sampling technique was used to select the patients.

\subsection{Inclusion Criteria}

Hypertension diagnosed adults aged between 21 to 85 years were enrolled in the study. Patients having clinic systolic BP (SBP) level (145-179 mm Hg) or clinic diastolic BP (DBP) level (95- 109 mm Hg) without indication of diabetes and patients with diabetes having clinic SBP level (135-179 mm Hg) or a clinic DBP (85$109 \mathrm{~mm} \mathrm{Hg}$ ), who were willing to take part in the study were included.

\subsection{Exclusion Criteria}

Patients whose medication or dose were changed within 4 weeks of the baseline visit, patients having stage III 
hypertension (BP >180/110 mm Hg) or with history of recent myocardial infarction or stroke (within 6 months before enrollment), congestive heart failure, unstable angina, serious renal or hepatic disease, pregnancy, poor prognosis (life expectancy $<3$ years), dementia and cognitive impairment were excluded from the study.

\subsection{Study Tool Used}

The first part of this tool was regarding patient's demographic data such as name, gender, marital status, address, age, visit date, duration of hypertension, body weight, blood pressure and awareness regarding organ damage. Health related quality of life was measured by using Urdu version of EQ-5D. This generic instrument was developed and translated by the EuroQoL group[28]. EQ-5D Index scale consist of 5 dimensions known as mobility, self care, usual activities, pain or discomfort and anxiety or depression. Each dimension has three levels such as no problem, some or moderate problem and extreme problem as level1, 2, and 3 respectively. All these dimensions and levels generated $3^{5}=243$ health states. Whereas unconscious and death states were added to complete health states from death (0) to full health (1) and negative score indicate worse health from death. The EQ5D preference weight for each health state was not available for Pakistani population, therefore these were derived from TTO tariff of preference weights of UK general population as EQ-5D Index score[1]. On the other hand EQ-5D VAS consisted $20 \mathrm{~cm}$ visual analogue scale. The end points of this scale were describing best health as ' 100 ' and worst health as ' 0 '. The patients were asked to mark their present health state on this scale[1,29]. EQ-5D index score and EQ-5D VAS were estimated for each patient at baseline and at follow up visits after 2 months, 4 months and 6 months.

\subsection{Data Analysis}

Demographic data and disease characteristics were presented through descriptive statistics. Percentages and frequencies were used for categorical data, whereas means and standard deviations were calculated for continues data. Paired t tests were performed for comparison of EQ-5D Index scores and EQ-5D VAS scores of repeated visits before and after intervention. Pearson's correlation coefficient ' $r$ ' was used to find relationship between baseline and follow up visits scores. While the statistical value of $\mathrm{p}<0.05$ was taken as significant. All the data was statistically analyzed by using SPSS version 16 .

\section{Results}

\subsection{Socio-demography Characteristics of Study Patients}

Altogether, there were 116 patients enrolled in the study. The mean age (in years) of the patients was $49.14 \pm 12.56$, with a median age (in years) and interquartile range (IQR) of 40 [(50)-(58)]. Males were greater in number $(n=81,69.8 \%)$ than females. Most of the patients $(n=31,26.7 \%)$ had history of hypertension for 6-10 years. On the other hand, ( $\mathrm{n}=91,78.4 \%)$ of the patients were unaware regarding hypertension. Further details about patients' demography are outlined in (Table 1).

Table 1. Socio-demographics

\begin{tabular}{|c|c|c|}
\hline \multicolumn{2}{|c|}{ Variables } & \multirow{2}{*}{$\begin{array}{c}\mathbf{n}(\mathbf{\%}) \\
81(69.8)\end{array}$} \\
\hline Condor & Male & \\
\hline Genduer & Female & $35(30.2)$ \\
\hline \multirow{6}{*}{ Age } & 25-34 years & $1(0.9)$ \\
\hline & 35-44 years & $13(11.2)$ \\
\hline & 44-54 years & $22(19.0)$ \\
\hline & 55-64 years & $47(40.5)$ \\
\hline & $65-74$ years & $22(19.0)$ \\
\hline & 74-85 years & $11(9.5)$ \\
\hline \multirow{2}{*}{ Marital Status } & Married & $106(91.4)$ \\
\hline & Widowed & $10(8.6)$ \\
\hline \multirow{7}{*}{ History of hypertension } & $\geq$ than year & $9(7.8)$ \\
\hline & 1-2 years & $21(18.1)$ \\
\hline & $3-5$ years & $22(19.0)$ \\
\hline & $6-10$ years & $31(26.7)$ \\
\hline & $11-15$ years & $14(12.1)$ \\
\hline & 16-20 years & $12(10.3)$ \\
\hline & $\leq 20$ years & $7(6)$ \\
\hline \multirow{2}{*}{ Awareness of organ damage } & Aware & $25(21.6)$ \\
\hline & Unaware & $91(78.4)$ \\
\hline
\end{tabular}

\subsection{Health Related Quality of Life}

At baseline the EQ-5D index and EQ-5D VAS scores of patients were $0.8789( \pm 0.17993)$ and $65.56( \pm 16.665)$ respectively while after six months of pharmaceutical care intervention, the EQ-5D index and EQ-5D VAS scores of patients were $0.9276( \pm 0.1397)$ and $78.00( \pm 12.649)$ respectively (Table 2$)$.

Table 2. Health related quality of life

\begin{tabular}{|c|c|c|c|c|}
\hline Statement & Baseline & $\begin{array}{c}\text { After two } \\
\text { months }\end{array}$ & $\begin{array}{c}\text { After four } \\
\text { months }\end{array}$ & $\begin{array}{c}\text { After six } \\
\text { months }\end{array}$ \\
\hline $\begin{array}{l}\text { EQ-5D Index } \\
\text { Score } \\
\text { Mean }( \pm \text { S.D) }\end{array}$ & $\begin{array}{c}0.8789 \\
\pm 0.17993\end{array}$ & $\begin{array}{c}0.9235 \\
\pm 0.12103\end{array}$ & $\begin{array}{c}0.9323 \\
\pm 0.10991\end{array}$ & $\begin{array}{c}0.9276 \\
\pm 0.13971\end{array}$ \\
\hline $\begin{array}{l}\text { EQ-5D VAS } \\
\text { Score } \\
\text { Mean ( } \pm \text { S.D) }\end{array}$ & $\begin{aligned} & 65.56 \\
+ & 16.665\end{aligned}$ & $\begin{array}{c}71.64 \\
+13.843\end{array}$ & $\begin{array}{c}76.77 \\
\pm 13.323\end{array}$ & $\begin{array}{c}78.00 \\
\pm 12.649\end{array}$ \\
\hline
\end{tabular}

\subsection{Self-reported (EQ-5D) Health States}

A total 17 different EQ-5D health states out of 243 health states were recorded in this study from the patients. At baseline 63 (54.3\%) patient had reported health state (11111) as these patients had no problem in five domains of EQ-5D and not bothered by the hypertension at baseline. On the other hand the health state of $16(13.8 \%)$ patients was 11112 which indicate that these patients had some anxiety or depression due to hypertension. Likewise the health state 21111 was in 9(7.8\%) patients described that these patients had problem in their mobility domain. Because of interventions, after six months the overall health states were improved which are reflected in Table 3. There were $77(66.4 \%)$ patients in health state 11111 , as these patients had no problem while the percentage of health state of 11112 decreased to 8(6.9\%) and the percentage of health state 21111 increased to 23(19.8\%). This increase was the result of the decrease in the percentages of other health states after six months particularly health states 21112, 21121, 22111, and 22222. 
All these figures reflect that overall quality of life is improved (Table 3).

Table 3. Frequency of self-reported (EQ-5D) Health States

\begin{tabular}{|c|c|c|c|c|c|c|c|c|c|c|c|c|c|}
\hline \multirow{2}{*}{$\begin{array}{c}\text { Health } \\
\text { States } 18\end{array}$} & \multicolumn{2}{|c|}{ Baseline } & \multicolumn{2}{|c|}{$\begin{array}{l}\text { After two } \\
\text { months }\end{array}$} & \multicolumn{2}{|c|}{$\begin{array}{l}\text { After four } \\
\text { months }\end{array}$} & \multicolumn{2}{|c|}{$\begin{array}{c}\text { After six } \\
\text { months }\end{array}$} & \multirow{2}{*}{\multicolumn{5}{|c|}{ between baseline and after 4 months and six months }} \\
\hline & $\mathbf{F}$ & $\%$ & $\mathbf{F}$ & $\%$ & $\mathbf{F}$ & $\%$ & $\mathbf{F}$ & $\%$ & & & & & \\
\hline 11111 & 63 & 54.3 & 73 & 62.9 & 74 & 63.8 & 77 & 66.4 & \multicolumn{5}{|c|}{$\begin{array}{l}\text { improvements in HRQoL. Atter pharmaceutical care } \\
\text { intervention, the median scores of EQ-5D were reported }\end{array}$} \\
\hline 11112 & 16 & 13.8 & 12 & 10.3 & 10 & 8.6 & 8 & 6.9 & \multirow{3}{*}{\multicolumn{5}{|c|}{$\begin{array}{l}\text { higher when compared after two, four and six months with } \\
\text { baseline respectively (Table 5). }\end{array}$}} \\
\hline 11113 & 1 & 0.9 & 0 & 0 & 0 & 0 & 0 & 0 & & & & & \\
\hline 11121 & 1 & 0.9 & 0 & 0 & 0 & 0 & 0 & 0 & & & & & \\
\hline 11211 & 1 & 0.9 & 0 & 0 & 0 & 0 & 0 & 0 & \multirow{2}{*}{\multicolumn{5}{|c|}{$\begin{array}{l}\text { Table 5. Comparison of EQ-5D VAS of repeated visits before and } \\
\text { after intervention Paired t-test } p \leq 0.05\end{array}$}} \\
\hline 11222 & 1 & 0.9 & 0 & 0 & 0 & 0 & 0 & 0 & & & & & \\
\hline 21111 & 9 & 7.8 & 16 & 13.8 & 24 & 20.7 & 23 & 19.8 & $\mathbf{n}$ & Mean & $\mathbf{t}$ & $\mathbf{r}$ & p-value \\
\hline 21112 & 5 & 4.3 & 5 & 4.3 & 3 & 2.6 & 3 & 2.6 & \multicolumn{5}{|c|}{ Baseline Vs After two months (After intervention first visit) } \\
\hline 21121 & 2 & 1.7 & 0 & 0 & 0 & 0 & 0 & 0 & \multirow{2}{*}{$\begin{array}{l}\text { Baseline = } 116 \\
\text { After } 2 \text { months = } 116\end{array}$} & Baseline $=65.56$ & \multirow{2}{*}{6.25} & \multirow{2}{*}{0.78} & \multirow{2}{*}{0.001} \\
\hline 21122 & 1 & 0.9 & 0 & 0 & 0 & 0 & 0 & 0 & & $\begin{array}{l}\text { After } 2 \text { months } \\
=71.64\end{array}$ & & & \\
\hline 21222 & 1 & 0.9 & 1 & 0.9 & 1 & 0.9 & 1 & 0.9 & \multicolumn{5}{|c|}{ Baseline Vs After four months } \\
\hline 22111 & 6 & 5.2 & 5 & 4.3 & 1 & 0.9 & 1 & 0.9 & \multirow{3}{*}{$\begin{array}{l}\text { Baseline }=116 \\
\text { After } 4 \text { months } \\
=116\end{array}$} & aseline $=65.56$ & \multirow{3}{*}{9.97} & \multirow{3}{*}{0.70} & \multirow{3}{*}{0.003} \\
\hline 22112 & 2 & 1.7 & 1 & 0.9 & 1 & 0.9 & 1 & 0.9 & & fter 4 months $=$ & & & \\
\hline 22221 & 1 & 0.9 & 1 & 0.9 & 1 & 0.9 & 1 & 0.9 & & .77 & & & \\
\hline 22222 & 5 & 4.3 & 1 & 0.9 & 0 & 0 & 0 & 0 & \multicolumn{5}{|c|}{ Baseline Vs After six months } \\
\hline 31112 & 0 & 0 & 1 & 0.9 & 1 & 0.9 & 1 & 0.9 & \multirow{3}{*}{$\begin{array}{l}\text { Baseline }=116 \\
\text { After } 6 \text { months }=116\end{array}$} & $\begin{array}{l}\text { Baseline }=65.56 \\
\text { After } 6 \text { months }=\end{array}$ & \multirow{2}{*}{6.54} & \multirow{2}{*}{.01} & \multirow{2}{*}{0.002} \\
\hline 32222 & 1 & 0.9 & 0 & 0 & 0 & 0 & 0 & 0 & & 78.00 & & & \\
\hline Total & 116 & 100 & 116 & 100 & 116 & 100 & 116 & 100 & & & & & \\
\hline
\end{tabular}

\subsection{Comparison of EQ-5D Index Scores of Repeated Visits before and after Intervention}

The differences between patients' health related quality of life EQ-5D Index scores before and after intervention were analyzed by using the paired t test. Patients' health related quality of life EQ-5D Index scores were found to be $(p \leq 0.05)$ statistically significant. The value of Pearson's correlation $r=.66(\mathrm{P}<0.5)$ between baseline and after two months which shows significant association. The values of ' $r$ ' were decreased between baseline and after 4 months and six months follow ups. That also indicates the significant improvements in HRQoL. After pharmaceutical care intervention, the median scores of patients' health related quality of life EQ 5D Index score were reported higher when compared after two, four and six months with baseline respectively (Table 4).

Table 4. Comparison of EQ- 5D Index scores of repeated visits before and after intervention Paired t-test $\mathrm{p} \leq 0.05$

\begin{tabular}{|c|c|c|c|c|}
\hline n & Mean & $\mathbf{t}$ & $\mathbf{r}$ & p-value \\
\hline \multicolumn{5}{|c|}{ Baseline Vs After two months (After intervention first visit) } \\
\hline Baseline = 116 & Baseline $=0.878$ & & & \\
\hline $\begin{array}{l}\text { After two months } \\
=116\end{array}$ & $\begin{array}{l}\text { After two months } \\
=0.923\end{array}$ & 3.55 & .66 & 0.001 \\
\hline \multicolumn{5}{|c|}{ Baseline Vs After four months } \\
\hline Baseline = 116 & Baseline $=0.878$ & & & \\
\hline $\begin{array}{l}\text { After four months } \\
=116\end{array}$ & $\begin{array}{l}\text { After four months } \\
=0.932\end{array}$ & 4.29 & .67 & 0.003 \\
\hline \multicolumn{5}{|c|}{ Baseline Vs After six months } \\
\hline $\begin{array}{l}\text { Baseline = } 116 \\
\text { After six months } \\
=116\end{array}$ & $\begin{array}{l}\text { Baseline }=0.878 \\
\text { After six months } \\
=0.923\end{array}$ & 2.24 & .05 & 0.002 \\
\hline
\end{tabular}

\subsection{Comparison of EQ-5D VAS of repeated visits before and after intervention}

The differences between patients' health related quality of life EQ-5D VAS scores before and after intervention were analyzed by using the paired t test. EQ-5D VAS scores were found to be $(\mathrm{p} \leq 0.05)$ statistically significant.

The value of Pearson's correlation $\mathrm{r}=.78(\mathrm{P}$

between baseline and after two months which shows significant association. The values of ' $r$ ' were decreased between baseline and after 4 months and six months follow ups. That also indicates the significant intervention, the median scores of EQ-5D were reported higher when compared after two, four and six months with

Table 5. Comparison of EQ-5D VAS of repeated visits before and

\section{Discussion}

Pharmacist, as one of the indispensable members of a health-care team, has a major role in improving patients' knowledge about hypertension and hence the quality of life outcomes. The present study was carried out to assess the impact of pharmacist-provided pharmaceutical care intervention on the health-related quality of life of hypertensive patients. It was found that pharmacistprovided counseling successfully improved the healthrelated quality of life (HRQoL) of hypertensive patients. The present study identified prevalence of hypertension more in males, which complies with the results of study conducted in China reporting that the male gender and residence in a developing country were factors associated with poor BP control [31]. This may be due to a disparity in health-seeking behavior among the two genders, and males might be getting more opportunity to access and avail themselves of diagnosis and treatment. However, the occurrence of hypertension was common in middle-aged (45-60 years) patients, which is in accordance with the findings from another study conducted in Finland [32]. The high incident rate of hypertension in middle-aged patients could be due to their busy and stressful life which could have affected their lifestyle and dietary habits and decreased physical activities.

Health related quality of life (HRQoL) is a multidimensional construct referring to an individual's perception of their position in life in the context of the culture and value systems in which they live and in relation to their goals, expectations, standards, and concerns [33]. Health-related quality of life (HRQoL) can be improved by promoting patients' care activities and supporting their quality of life domains [34]. HRQoL is a multi factorial phenomenon and is independent to a single factor. Hypertension is a chronic illness that requires lifelong treatment. The developing countries are facing a number of challenges in providing optimal health care to 
all of its populations. In Pakistan, health services are very expensive and majority of health care costs are paid by patients themselves. The cost of health care for chronic diseases puts a significant strain on household budgets and pushed these patients into poverty which decreases their HRQoL (Saleem et al., 2012c). In addition, lack of basic health facilities and resources, behavioral aspects and practices influence the patient in real-life situation. In return, a large number of patients tend to move to other healthcare providers like Homeopaths and Hakeems (Unani-Tib) prior to consulting certified practitioners. Prevalence of such entities affects the HRQoL to more extent than it is believed, hence increasing the cost of therapies and decreasing the HRQoL [35]. The results of the present study reported low scores of health related quality of life in hypertensive patients at baseline. Similar results of adverse effect on patients' well-being and HRQoL due to hypertension were reported by another study conducted in Pakistan [25].

\section{Conclusion}

Pharmacist involvement in chronic disease management can make a positive impact on patients' health-related outcomes. Pharmacist counseling empower patients' knowledge and self-care skills to understand ways to cope with such a situation and can help them to achieve a better quality of life. Hypertension is still a challenge for healthcare professionals, and the role of the pharmacist in improving patients' health-related quality of life is only theoretical and not practical in Pakistan. The results of the present study proved that pharmaceutical care intervention provided by a pharmacist can improve the health-related quality of life (HRQoL) of hypertensive patients

\section{Limitations}

The study was conducted with a small number of hypertensive patients who were selected from only one hospital of the Punjab province of Pakistan and hence the study findings might not be able to generalize to the entire hypertensive population of the country.

\section{References}

[1] Dolan, P., et al., A social tariff for EuroQol: results from a UK general population survey. 1995: Centre for Health Economics University of York, UK.

[2] Theodorou, M., et al., Quality of life measurement in patients with hypertension in cyprus. The Hellenic Journal of Cardiology, 2011. 52(5): p. 407-415.

[3] Erickson, S.R., B.C. Williams, and L.D. Gruppen, Relationship Between Symptoms and Health-Related Quality of Life in Patients Treated for Hypertension. Pharmacotherapy: The Journal of Human Pharmacology and Drug Therapy, 2004. 24(3): p. 344-350.

[4] Norman, G.R., J.A. Sloan, and K.W. Wyrwich, Interpretation of changes in health-related quality of life: the remarkable universality of half a standard deviation. Medical care, 2003. 41(5): p. 582-592.

[5] Wilson, I.B. and P.D. Cleary, Linking clinical variables with health-related quality of life: a conceptual model of patient outcomes. Jama, 1995. 273(1): p. 59-65.

[6] WHO, A., Global Brief on Hypertension. World Health Organization, 2013.
[7] Schipper, H., J. Clinch, and C.L. Olweny, Quality of life studies: definitions and conceptual issues. Quality of life and pharmacoeconomics in clinical trials, 1996. 2: p. 11-23.

[8] Hayes, D.K., et al., Health-related quality of life and hypertension status, awareness, treatment, and control: National Health and Nutrition Examination Survey, 2001-2004. Journal of hypertension, 2008. 26(4): p. 641-647.

[9] Trevisol, D.J., et al., Health-related quality of life and hypertension: a systematic review and meta-analysis of observational studies. Journal of hypertension, 2011. 29(2): p. 179-188.

[10] Korhonen, P.E., et al., Health-related quality of life and awareness of hypertension. Journal of hypertension, 2011. 29(11): p. 20702074.

[11] Poljičanin, T., et al., Diabetes mellitus and hypertension have comparable adverse effects on health-related quality of life. BMC Public Health, 2010. 10(1): p. 12.

[12] Hepler, C.D. and L.M. Strand, Opportunities and responsibilities in pharmaceutical care. Am J Hosp Pharm, 1990. 47(3): p. 533-43.

[13] Planas, L.G., et al., A pharmacist model of perceived responsibility for drug therapy outcomes. Social science \& medicine, 2005. 60(10): p. 2393-2403.

[14] Lyra Jr, D.P., et al., Influence of Pharmaceutical Care intervention and communication skills on the improvement of pharmacotherapeutic outcomes with elderly Brazilian outpatients. Patient Education and Counseling, 2007. 68(2): p. 186-192.

[15] Júnior, L., P.S. Marcellini, and I.R. Pelá, Effect of pharmaceutical care intervention on blood pressure of elderly outpatients with hypertension. Revista Brasileira de Ciências Farmacêuticas, 2008. 44(3): p. 451-457.

[16] Lee, J.K., K.A. Grace, and A.J. Taylor, Effect of a pharmacy care program on medication adherence and persistence, blood pressure, and low-density lipoprotein cholesterol. JAMA: the journal of the American Medical Association, 2006. 296(21): p. 2563-2571.

[17] Zillich, A.J., et al., Hypertension outcomes through blood pressure monitoring and evaluation by pharmacists (HOME study). Journal of general internal medicine, 2005. 20(12): p. 1091-1096.

[18] Vivian, E.M., Improving blood pressure control in a pharmacist-managed hypertension clinic. Pharmacotherapy: The Journal of Human Pharmacology and Drug Therapy, 2002. 22(12): p. $1533-1540$

[19] Roter, D.L., et al., Effectiveness of interventions to improve patient compliance: a meta-analysis. Medical care, 1998. 36(8): p. 11381161.

[20] Morisky, D.E., et al., Predictive validity of a medication adherence measure in an outpatient setting. The Journal of Clinical Hypertension, 2008. 10(5): p. 348-354.

[21] Carter, B.L., et al., Evaluation of hypertensive patients after care provided by community pharmacists in a rural setting. Pharmacotherapy: The Journal of Human Pharmacology and Drug Therapy, 1997. 17(6): p. 1274-1285.

[22] Pickard, A.S., J.A. Johnson, and K.B. Farris, The impact of pharmacist interventions on health-related quality of life. The Annals of pharmacotherapy, 1999. 33(11): p. 1167-1172.

[23] Krousel-Wood, M., et al., Medication adherence: a key factor in achieving blood pressure control and good clinical outcomes in hypertensive patients. Current opinion in cardiology, 2004. 19(4): p. 357-362.

[24] Page, I.H., Drug treatment of hypertension. 1966: Springer.

[25] Saleem, F., M.A. Hassali, and A.A. Shafie, A cross-sectional assessment of health-related quality of life (HRQoL) among hypertensive patients in Pakistan. Health Expectations, 2012.

[26] Palaian, S., et al. (2005) Role of pharmacist in counseling diabetes patients. The Internet Journal of Pharmacology 4.

[27] Khanal, S., et al., Oncology pharmacy practice in a teaching hospital in Nepal. Journal of Oncology Pharmacy Practice, 2010. 16(2): p. 75-79.

[28] EuroQol, G., EuroQol--a new facility for the measurement of health-related quality of life. Health policy (Amsterdam, Netherlands), 1990. 16(3): p. 199.

[29] Dolan, P., Modeling valuations for EuroQol health states. Medical care, 1997. 35(11): p. 1095-1108.

[30] Leventhal, H. and D.R. Nerenz, A model for stress research with some implications for the control of stress disorders, in Stress reduction and prevention. 1989, Springer. p. 5-38. 
[31] Lam, C.L. and I.J. Lauder, The impact of chronic diseases on the health-related quality of life (HRQOL) of Chinese patients in primary care. Family Practice, 2000. 17(2): p. 159-166.

[32] Pyorala, K., J. Salonen, and T. Valkonen, Trends in coronary heart disease mortality and morbidity and related factors in Finland. Cardiology, 1985. 72(1-2): p. 35-51.

[33] WHO, WHOQOL-BREF: introduction, administration, scoring and generic version of the assessment: field trial version, December 1996. 1996.
[34] Saleem, F., M.A. Hassali, and A.A. Shafie, A cross-sectional assessment of health-related quality of life (HRQoL) among hypertensive patients in Pakistan. Health Expectations, 2012.

[35] Ul Haq, N., et al., A cross sectional assessment of health related quality of life among patients with Hepatitis-B in Pakistan. Health Qual Life Outcomes, 2012. 10(1): p. 91. 